\title{
BehSys Anal: An artificially intelligent hypermedia resource library for descriptive behavioral research
}

\author{
ROGER D. RAY and NANETTE MITCHELL \\ Rollins College, Winter Park, Florida
}

\begin{abstract}
The advancement of computer technologies, particularly the development of hypertext and interactive video, has presented to the academic community a new and effective tool for teaching and learning. An application of these technologies led to the concept of a hypermedia resource library-a set of integrated interactive computer modules that allow the user to browse and study topically specific content in a unique way. Such modules electronically present textual, graphic, and realtime video materials that instruct and quiz the user, offer a means for computer-based laboratory experimentation and data analysis, and provide statistical evaluation of the user's progress. This paper will focus on the technology of computer-based hypermedia and the specific concept within this context of the artificially intelligent hypermedia resource library.
\end{abstract}

Psychology, as with most academic disciplines, is typically taught in a linear fashion that progresses topically to higher and higher degrees of detail and specialization. Thus an introductory psychology course will typically include a survey of specialized topics, including learning, personality, social psychology, developmental psychology, physiological psychology, perception, cognition, and so forth. Upper-division courses are similarly recognizable by their more in-depth introduction to these same topics and include full courses on learning, personality, social psychology, and so forth. Advanced undergraduate and graduate courses offer more detail on these same topics, although they sometimes focus on subtopics within the main topic, for example, aggression as a subspecialization of social psychology.

Almost all teachers working within such educational curricula have, over their careers, developed their own personal collections of resources that support their teaching of these different levels of topical specialization. Teachers may have favorite films, slides, and overhead transparencies they use in the introductory course to supplement various lectures and reading assignments, including readings in the primary text and those assigned and/or recommended that supplement the text. In advanced courses, teachers may rely on more specialized secondary readings, such as a topical introductory text plus personalized collections of primary readings that illustrate pet concepts or points of interest. At this level, films and other audiovisuals are more specific and tailored to the advanced topical interests and elaborations. Teachers typi-

Research and program development reported in this paper were funded in part by NSF-ILI Grant USE-8952419. Correspondence should be addressed to R. D. Ray, Rollins College, Department of Psychology, 1000 Holt Ave.-2760, Winter Park, FL 32789; e-mail: rdray@rollins. cally strive to maintain and update personalized libraries of the various teaching resources they wish to keep at their fingertips to meet their instructional needs.

With the increasing availability and sophistication of personal computers, the development of computer-based instructional materials has advanced significantly to augment the various audiovisual materials available. For example, there is currently a wide variety of topically specific educational video laser discs and a rapidly expanding choice of experimental computer simulations. Likewise, computers are being used as substitutes for text delivery, tutoring, and evaluation. In this article, we wish to demonstrate how some newly advancing computer technologies and these historical needs for topical resource libraries are coming together to create a radically new form of teaching and learning-the artificially intelligent hypermedia resource library.

A topical hypermedia resource library includes modularized materials based on textual readings, audio explanations and instructions, fixed and animated graphic illustrations, computerized simulations, and full-motion digital video amplifications of content. These elements are semirandomly accessed via any one of a multitude of paths, making for a nonlinear presentation that is unique for each person using the library. It involves computer-assisted instruction and evaluation as well as a self-tracking capability for assessing what a user has and has not accessed.

In addition, the library includes both an artificial intelligence (AI) engine and an automated knowledge generator (AKG). The AI engine is based upon the concepts being taught by the library's text modules and is an illustrated application of the data-analysis modules supplied. Its primary purpose is to guide the user to hyperlinks that have been left unexplored (guide mode) or to test the user's knowledge and skills (study mode) with respect to the content and usage of the library's materials. The AKG 
supplies knowledge to the $\mathrm{AI}$ engine but also generates a database that allows instructors to analyze and compare students' learning strategies. In addition to supplying instructors with the usual performance feedback, such as number of correct/incorrect questions, the AKG supplies standard behavioral systems measures (see Ray \& Delprato, 1989) of the user's behavior, including topic-access frequency, mean duration, total time per topic and subtopic, path of sequence and access, and so forth. These portions of the library, along with the navigational strategies and presentation designs, also constitute a HyperCard-based authoring system for additional module development.

The primary purpose of this paper is to introduce the concept and power of hypermedia resource libraries as course supplements to standard library and laboratory assignments. A description of one specific resource librarythe Behavioral Systems Analysis (BehSys Anal) Hypermedia Resource Library-demonstrates the major functions and features of such a library as a teaching tool, a tutoring and evaluative tool, and a data-analysis tool. In addition, development issues are discussed with comments on the potential this technology offers for directed research.

\section{THE CONCEPT AND POTENTIAL OF HYPERMEDIA}

Many of us have vivid memories of our parents listening to Lowell Thomas's newscasts every evening on a console radio. If we could have told them that someday they could sit in front of a similar, if modified, console and actually see such a newscaster deliver the news in person, they might have envisioned seeing $\mathrm{Mr}$. Thomas in the radio studio addressing the world via a rather bulky microphone placed on a table in front of him. After all, movies already had primed us with such images of how news broadcasters worked.

Unlike this false image, the reality of modern newscasting is the anchor person, free of interceding microphones, who introduces a multitude of stories, often with an illustrative graphic superimposed over his/her shoulder to pique the viewer's interest. "Introduce" is emphasized because most news coverage then quickly switches to an on-location, full-motion video-clip presentation of the story as it happened, plus an audio overlay of a field reporter interpreting the event's significance for a viewing audience. The evening television newscast is thus a montage of human/graphic introductions, brief but informative motion-video clips (including the infamous "sound bite"), and audio interpretations designed to inform while maintaining maximal viewer attention.

It has taken approximately $\mathbf{5 0}$ years for education to launch similar transitions to the presentation of information. And, as with the transition from radio to television, technological advances are at the root of this transition. The educational analog of the radio-studio broadcaster is the traditional large-class lecturer standing in front of a chalkboard (or an overhead-transparency projector). But that model is ever so slowly giving way to a technologi- cally sophisticated model of teachers as knowledge navigators and informational-resource developers who work primarily to develop computer-accessed and multimedia delivered resource libraries that support a given topic of student interest. These resource libraries are accessed by a computer workstation capable of presenting text, audio, animated graphics, and simulations, as well as fullmotion video. Such presentations typically utilize what is called a hypermedia approach to material access, wherein the student user can exit any portion of a complex montage of informationally integrated multimedia modules at any time and immediately navigate to other portions or modules (Ambron \& Hooper, 1988).

But unlike the modern television newscast, students using hypermedia resource libraries can pursue topics to greater and greater depth as well as breadth. It can be likened to a futuristic image of newscasting where the TV news, the daily newspaper, the weekly news magazine, and even complex encyclopedias of related background and detail are incorporated into one integrated, on-line package, giving the viewer the opportunity to constantly scan the informational news bank by topic, geographical region, personalities, economics, and so forth, to see which story, and in what depth, he/she wishes to access. Then, just as the deepest region, say the in-depth background piece from the weekly news magazine, had been explored, up comes an opportunity to read related commentaries, historical summaries, and interpretative essays on the story.

The hypermedia resource library concept has at least two distinct applications. One is in the classroom, where lectures become animated presentations of overviews and opportunities extant in the library. Lecturers present an overview of persons and ideas represented in the library and why they were included. That is, they offer previews and context for subsequent use. They also demonstrate the various paths one might navigate to pursue a personal interest, including the teacher's. From this perspective, the instructor has at hand a teaching/lecturing resource library, whereby the lecture outline, graphic illustrations, and even relevant motion-video clips work very much like the evening TV news show. Students may be more interactive by asking questions and pursuing clarifications during a lecture; however, they are not in charge of the presentation, but rather rely upon the expertise of the "news editor" (in this case, the teacher) to inform them of the most important and interesting "stories of the day" (in this case, content areas).

The second, and far more important, application of hypermedia resource libraries follows such in-class presentations and overviews with opportunities for students to independently query and study the library outside of class. Here the student is in charge of pursuing those laboratory simulation projects, video background pieces, and the corpus of available text and supplemental auditory commentaries of that text that most immediately serve his/her interest. Sophisticated resource libraries tempt the cautious or timid student to view unexplored topics and 
offer them self-testing opportunities to evaluate how well they are learning the material. Such artificially intelligent systems will offer reviews or alternative presentations of underaccomplished materials and will enhance the learn-ing process by asking students questions based on their previous responses. Libraries also allow for automated knowledge acquisition processes that inform developers and/or researchers on the learning stylistics of individual users by recording durations, frequencies, and paths of material access.

\section{THE BEHSYS ANAL LIBRARY}

The BehSys Anal library was conceived as a set of integrated resource modules to be used to supplement courses on descriptive research methodologies and psychophysiological applications. Authored in HyperCard and compiled BASIC, it is composed of three major components: (1) the quick-start instruction manual, which introduces the mechanics, logic, and philosophy of both the BehSys Anal library and the hypermedia concepts upon which it is based; (2) the text and instructional modules, which include an electronic hypertext version of the user's manual and electronicmultimedia-enhanced (including interactive video) journal articles that offer relevant background readings on behavioral systems methodology; and (3) the data-analysis modules, which include a hypermedia, interactive-videobased approach for descriptive behavioral and physiological database management, analysis, and graphic summary archiving.

To introduce and illustrate the concept of an artificially intelligent hypermedia topical resource library, we briefly explore a few of the major features of the BehSys Anal library, including (1) nonlinear navigation, (2) the varied media modalities incorporated, including interactive video and an animated graphic simulation of operant conditioning, and (3) the browse, guide, and study modes of library operation and the AI and AKG engines that enable these modes.

\section{Navigation Strategies}

One of the most common complaints of those using hypertext documents is the ease with which one gets lost in the complex array of nonlinearly accessed content (Martin, 1990). Thus, the first problem dealt with in the design of the BehSys Anal library was that of creating navigational prompts and aids. Each of these navigational aids has its own function to guide the user through alternative content sections and through the varying paths and levels of content material. A student using the resource library begins by clicking on a HyperCard stack icon called BehSys Anal. A title page, or frontispiece (Figure 1), then appears that offers a choice of the three major component alternatives: (1) the instruction mode, (2) the analysis mode, or (3) the quick-start instructions. A typical first-time user will begin by clicking the quick-start instructions, which causes the frontispiece of this module to appear.

For further information, the first page of the quick-start instructions (Figure 2) offers five choices arranged in bulleted ( $\bullet$ ) sections: (1) a prologue, (2) a review of navigational standards used in the BehSys Anal library, (3) information on the various hypermedia concepts incorporated and illustrations of each, (4) a list of all resources included within the library, and (5) a brief introduction to the AI engine that drives the guide and study modes of library operation. Also, a message at the bottom of this screen explains that clicking on any bulleted item will bring more detail on that topic. When a given bulleted section is mouse-clicked, that chosen section becomes highlighted, giving visual verification of the selection activity. For example, clicking on "• A Review of Navigational Aids used in the Library" highlights this item, and a new screen appears that offers a choice of

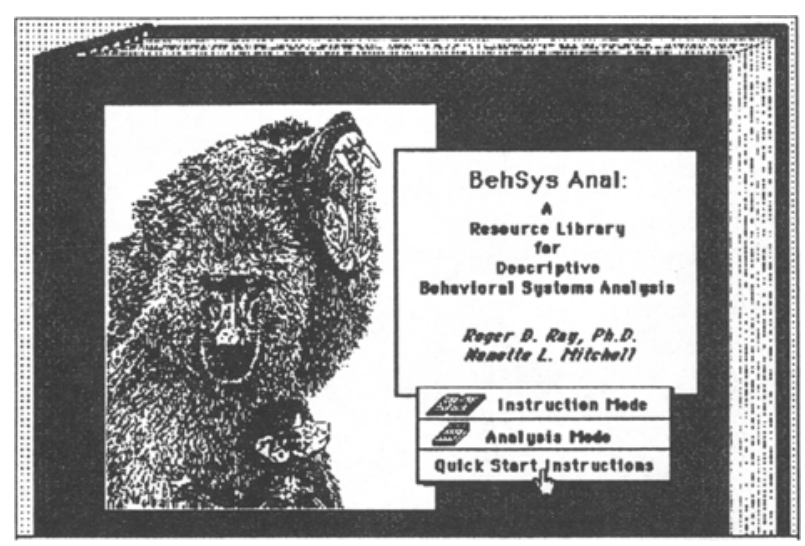

Figure 1. Mllustration of the frontispiece from which all components of the BehSys Anal library are accessed by clicking on either (1) instruction mode, (2) analysis mode, or (3) quick-start instructions.

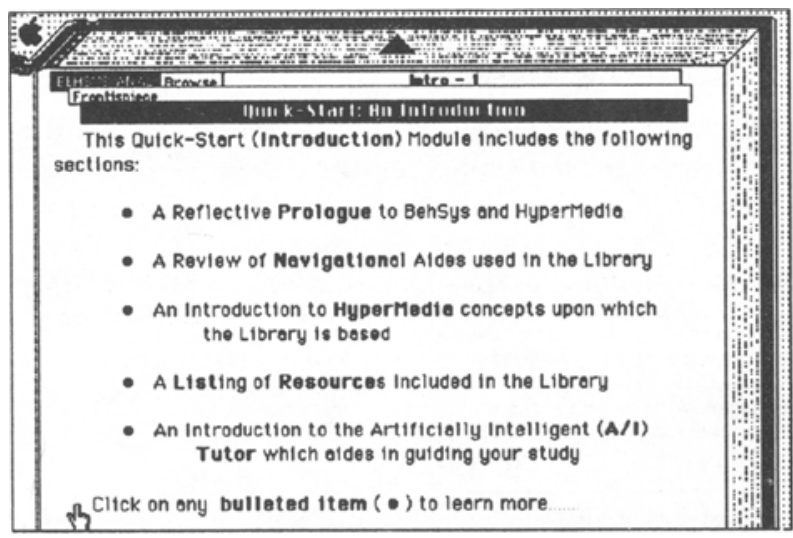

Figure 2. First page of the quick-start instruction manual illustrating a typical page layout and navigational aides. 
two alternative navigational strategies (i.e., the existence of different strategies for instructional and statistical modes). Clicking on the bulleted instructional alternative brings a succession of screens that provide more information about the specific navigational strategies used in the instructional modules.

These various screens include elaborative explanations of how to navigate from topic to topic by clicking (1) any words (text) marked by a bullet marker ( $\bullet$ ), (2) any highlighted text or graphic pictures (icons), (3) any italicized words, and (4) standards established by HyperCard itself (such as arrow icons) or by the BehSys Anal library. Several standards established by the library itself are depicted in Figure 2, including (1) the highlighted rectangular section at the upper left of the "open-book" page; (2) the level/page guide, which tells the reader the topical organization and level of content nesting of that page's materials, as depicted by the boldly printed "Intro - 1" in the uppermost white rectangle (this rectangle is what HyperCard calls a "field"); (3) the navigational access path in the white field holding the word "Frontispiece"; (4) the topical header, which is the highlighted field in the center upper portion of the page labeled "Quick-Start: An Introduction"; (5) the depth arrow icon embedded into the upper portion of the unopened pages of the book graphic; and (6) any graphic icons besides the arrow (none shown in Figure 2).

Clicking on any word segment of the navigational access path label will take the reader directly to the card represented by that segment. In Figure 2, the first card of the quick-start instructions module, only "Frontispiece" is showing in the access-path field. In most circumstances, the entire topical lineage of a card is available to the user, with any component of that lineage directly accessible. The depth arrow takes a reader to a more sophisticated and/or elaborate textual elaboration of

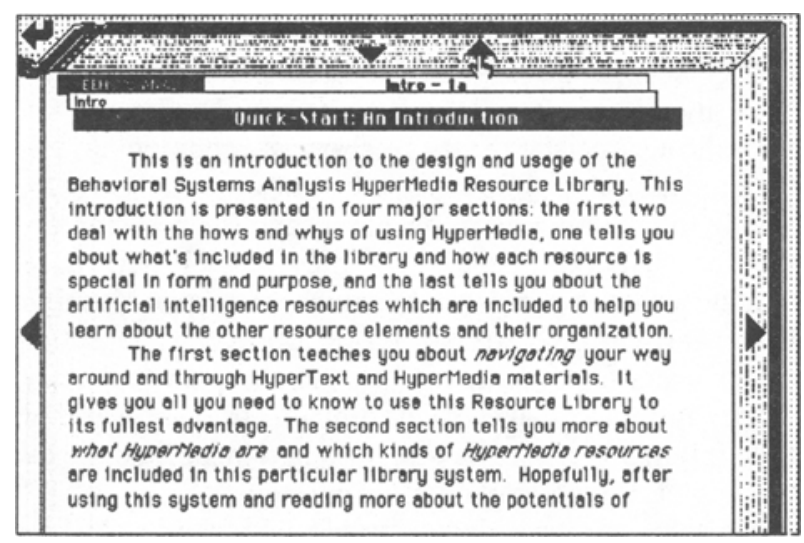

Figure 3. Ilustration of a second-level depth unit corresponding to the first-level page illustrated in Figure 2. Note the depth arrows at the top of the page allowing the user to return to the original Level 1 or a deeper Level 3. Note also that as deeper layers are accessed, a greater proportion of the book appears to open.

\begin{tabular}{|c|c|}
\hline $\begin{array}{c}\text { prier } \\
\text { related } \\
\text { torms }\end{array}$ & \\
\hline TERH: & Science \\
\hline $\begin{array}{l}\text { sueveedles } \\
\text { related } \\
\text { terms }\end{array}$ & $\begin{array}{l}\text { Philosophy of Science } \\
\text { Epistemolosy } \\
\text { Knovledge } \\
\text { Peredigmo }\end{array}$ \\
\hline $\begin{array}{l}\text { DEFINITION: } \\
\text { Other Usage }\end{array}$ & $\begin{array}{l}\text { 1. Knawledge, in the form of isolated focts ond integrative } \\
\text { principles, goined by systematic study. Such systematic } \\
\text { study involves disciplined, or rule governed, observation and } \\
\text { anelysis. } \\
\text { 2. A set of rules, or knowledge perodigm, which disciplines } \\
\text { observotion and enalysis in the pursult of scientific }\end{array}$ \\
\hline $\begin{array}{c}\text { Make Cards } \\
\text { Find } \\
\text { Find Nert } \\
\end{array}$ & 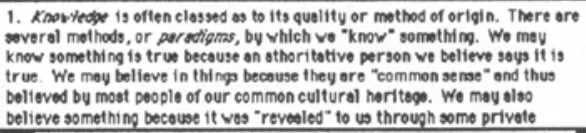 \\
\hline & Intro/Ayglind/Tye/Ref \\
\hline
\end{tabular}

Figure 4. Illustration of the first page of the BehSys Anal library's glossary of technical terms. Each glossary page includes prior and succeeding terms that are conceptually associated to the primary term, plus formal definitions and informal commentaries on usage and qualifications. Prior and succeeding terms may be directly accessed by clicking on the term in question. Any term may be found by clicking on the "find" button and typing the term requested.

the topics covered on a given screen (Figure 3). Levels are immediately traversed by clicking on arrows accessing deeper levels of the book or returning to earlier levels. As envisioned at present, topical resource libraries should incorporate at least four conceptual levels: (1) a "Cliff Notes"-type overview of material, (2) an introductory level of discourse, (3) a professional level of discourse, and (4) a directly accessed corpus of associated primary reference articles elaborating the material.

In addition to the navigation strategies for access within and between topics, strategies were developed for access to desktop study aids, such as the glossary and note cards. Menu selection allows access to a specialized comprehensive glossary of conceptually related terms in ascending/descending degrees of association, together with a formal definition of each term and a commentary on the definition that aids in understanding context and usage (Figure 4). Also, a note-card system is incorporated into the library that allows a user to keep page-specific notes in a simple text field merely by choosing a menu item to access the note pad. Likewise, when all notes are completed, a menu selection under the menu label "File" allows the user to print a complete file of all notes taken, fully page/topic marked and suitable for printing.

\section{Media Modalities in Hypermedia}

The third bulleted item in Figure 2 is "• An Introduction to HyperMedia concepts upon which the Library is based," and clicking on this item brings a similar listing of options offering opportunities to experience various illustrations of the multimedia capacities of the library. Only a few of these capacities can be appreciated in the present context of describing them verbally, since most rely upon sound and animation for their impact-which is why they 
are better than print media for their educational purposes in the first place. Nevertheless, a list of specific illustrations is instructive.

Sound. Merely by accessing some screens, or by clicking on an icon of an audio speaker on others, one starts the playback of a digital recording (recorded via a MacRecorder unit) of various explanations and instructions that aid the user. In addition, music may be played for emphasis or soundtracks used for comparative illustration (e.g., comparing the sounds of songbirds reared in audio isolation vs. those reared socially).

Animated graphics. Many topics related to behavior require movement, or kinetic qualities, for clear illustration. Differences in the gaits of animal locomotion is but one example. Likewise, teaching new students how to describe behavior using a formal taxonomy is best accomplished by illustrations of the behavioral codes that incorporate animated sequences. We could use full- or slow-motion video, but these images frequently are too complex for the primary effects we wish to illustrate. Thus, the BehSys Anal library incorporates several animated graphic cartoons of experimental arrangements and animal behaviors that allow the student to focus exclusively on the salient features of interest.

Interactive simulations. Graphic animations like those described above rely on a specific and unchanging script for animal movement and actions. Computer software has finally evolved to the point that creative designers, artists, and programmers are able to bring interactivity to animated graphics. The BehSys Anal library has two such interactive graphic simulations already incorporated: (1) a polygraph simulator that reads digital physiological data from a file and simulates the paper-tracing activities of a real polygraph and (2) a real-time cartoon animation of a monkey in a forest of trees (Figure 5) that may be trained, via standard operant shaping and reinforcement procedures, to increase the probability of various behaviors in its repertory or to evolve new ones from their components, much as real animals do in live demonstration experiments. The reinforcement is a group of bananas that are eaten, one by one, until they are gone.

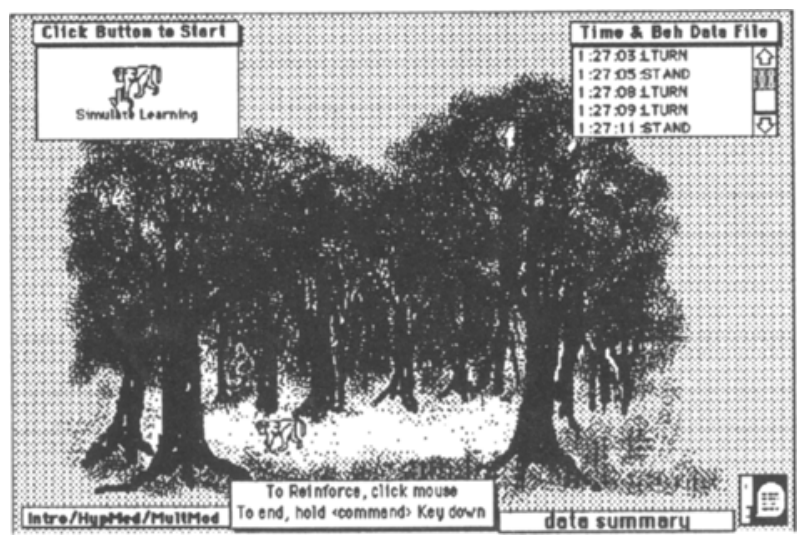

Figure 5. User-level card of the animated operant-conditioning simulation program.
Digital slides. With the advent of high-resolution computer graphics, we have the capability of delivering highquality (24-bit; 16 million colors) electronic pictures as substitutes for the traditional still picture or $35-\mathrm{mm}$ slide. In fact, several commercial presentation packages incorporate an easy interchange between attractive presentations of text "slides" and picture graphic "slides." HyperCard, and thus the BehSys Anal library, incorporates this technology as well. Very high quality still pictures are used liberally to illustrate concepts and objects.

Video clips. The same graphic capabilities that brought electronic slides to the computer also have now evolved to incorporate full-motion 24-bit color video capabilities into hypermedia applications. The BehSys Anal library incorporates this feature as well. Video clips are used to provide historical background and to teach and demonstrate concepts. One of the best illustrations of the library's use of video resides in the analysis mode, which is discussed later.

\section{Artificially Intelligent Tutoring and Automated Knowledge Generation}

The BehSys Anal library goes beyond allowing the user to navigate complex paths of content and to interact by making notes on text. It also incorporates an artificially intelligent guidance and tutorial/evaluation system. The library is used in one of three user modes: (1) browse, (2) guide, or (3) study. In the browse mode, the user is left entirely alone and no prompts, questions, or reminders are apparent. In the guide mode, the system tracks the user and presents reminders that various pages have already been read/studied (by imposing a "dog ear" on the page and by turning it black if a study guide for that page has been accessed). The system also prompts users about to leave a page to return to previous levels of material. It suggests various alternative paths of potential interest that have not yet been pursued and lists those sections not yet accessed. In the study mode, readers are randomly asked questions at various levels of difficulty. They may be multiple choice, fill-ins, topical associations that are prompted by a given term (e.g., the prompt may be Pavlov, and the topical associations may be classical conditioning, salivation, Russian physiologist, etc.), or unprompted (e.g., asking the main topic of this paragraph, then asking further for a list of its detailed subtopics). Finally, the reader may be asked to perform a behavioral task (such as finding an article on "stress" in the library). The system tracks users for both time (fluency) and path (accuracy) information and makes suggestions as to what materials they might want to review and/or new materials to read to supplement their understanding.

Thus far we have demonstrated how the user of the BehSys Anal library can easily explore varying paths and levels of complexity of a specific topic. As exploration progresses, the user is presented with audio explanation and a rich visual variety of animated graphics, digital slides, and video clips. Laboratory skills can be developed by the use of interactive simulations, and the user has immediate access to a specialized glossary and note- 
taking capabilities as well. In addition, the AI and AKG engines allow for guided exploration through the library's resources and periodic evaluation of user knowledge acquisition, while providing instructors with valuable data about student study and learning behavior.

Not only does the BehSys Anal library generate data, but it also provides a unique system for analyzing these data and archiving results. Let us thus turn to a brief description of the BehSys Anal library statistical and database management components to illustrate how interactive video is used as a database component of the library.

\section{The Statistical-Analysis Mode}

Figure 1 illustrates the option of accessing an analysis mode of the library, thus suggesting that this is not just a passive informational library, but also one allowing maximal user interaction and productivity in the area of behavioral systems analysis. The statistical-analysis package includes a HyperCard database management system that organizes quick and logical access to (1) various kinds of data to be analyzed (behavioral, physiological, or physiological data with behaviors as "setting" variables), (2) observational-experimental groups, (3) individual subjects within those groups, and (4) specific observational sessions, or files, for each subject (Figure 6). The HyperCard data manager offers users two modes of operation of its own: (1) active data analysis and graphic summary generation and (2) passive browsing of previously stored graphic and numerical data summaries. All data analyses are accomplished via external calls to compiled BASIC programs for purposes of increasing processing speed and in some cases graphics-production speed.

Consider, as one illustration, the desire to view a simple time-series plot of both behavioral states, as categorically described via a coding system, and concomitant heart rate, across a given 30-min observational session. The library incorporates a demonstration unit that illustrates how users might build their own such databases, but also includes a demonstration unit based on a real experiment. The experiment is represented by a single 30 min observational session of a targeted adult male (Beta) baboon living socially with 4 other baboons (another adult [Alpha] male, 2 adult females, and an infant). This targeted subject is wearing a backpack telemetry unit that is transmitting cardiovascular data on heart rate, blood pressure, and blood flow from the renal and femoral ar-
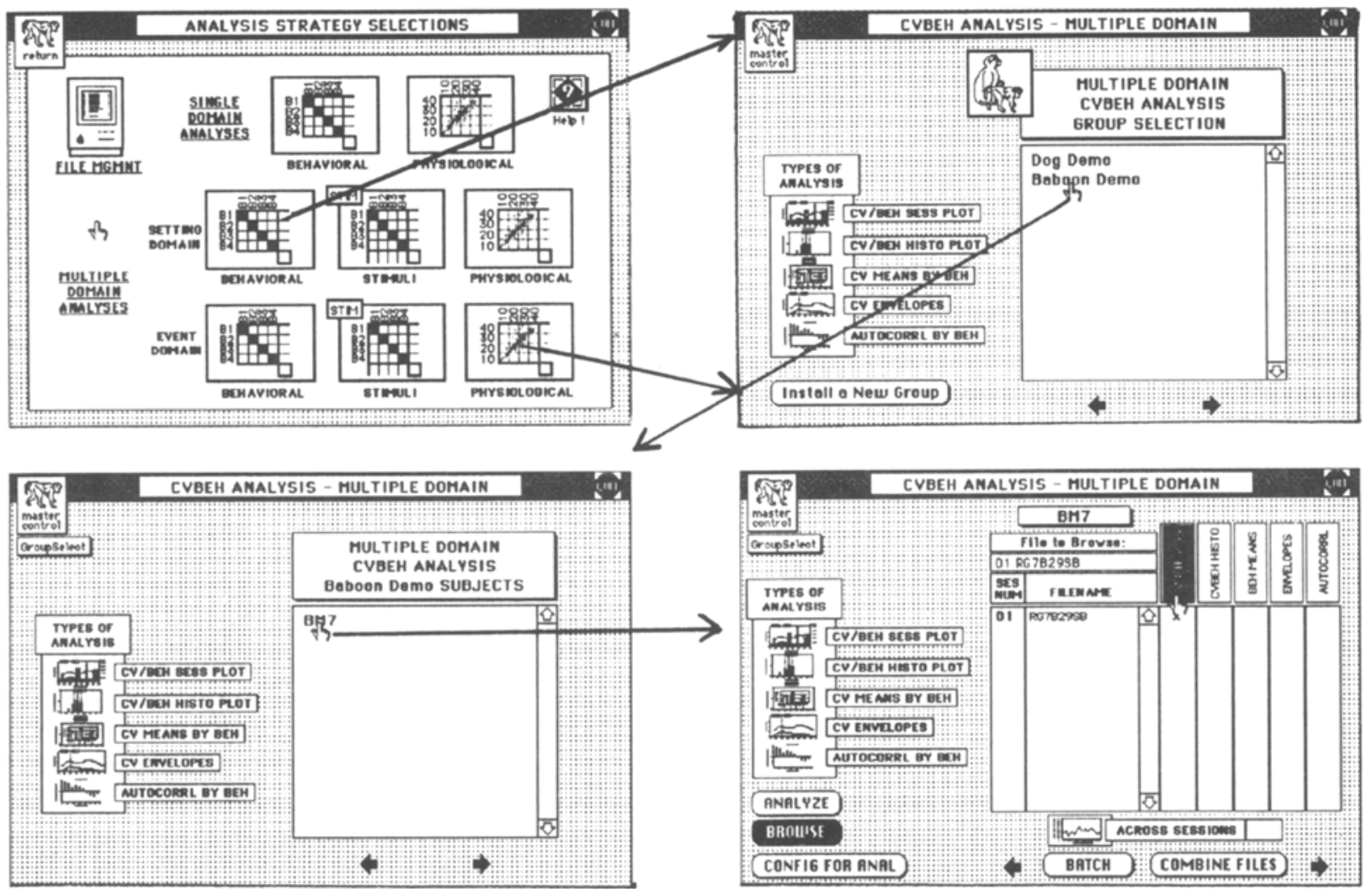

Figure 6. The analysis strategy selection level of the database management and analysis system. By clicking on the pictured matricies, each of which symbolizes a form of analysis strategies available, the user is able to rearrange file structures (file management) or analyze and store graphical/numerical summaries of behavioral kinematics, physiological summaries, or physiological summaries within behavioral and behavioral-sequence conditions. Illustration of screen series accessed from this card include the group, subject, and file-selection cards in the statistical data-management stacks. 
teries (Astley et al., 1991). Included in the library is a laser-disc video recording of this demonstration session plus the fully digitized behavioral and physiological database recorded from the session.

To view the time series desired, the behavior-as-setting and the physiology-as-behavior icons are clicked (lower half of the analysis strategies card in Figure 6). This selection takes the user to a series of cards from which the experimental group, subject, and data file may be chosen (from the baboon demo, Beta male, and demo file cards, respectively). Clicking the file name and the appropriate analysis then brings the user to a data summary card (Figure 7), whether it is being created for the first time (analysis mode) or is a previously posted graphic result the user wishes to view (browse mode).

Assume the user is interested in pursuing details of this rather dense summary graphic. For example, the rapid acceleration of heart rate depicted in the first 5 min may be of particular interest. Clicking on the graph anywhere during that time period brings us a more detailed beatby-beat view of the heart rate plot that corresponds to the initial summary section (Figure 8). Note the anomalous

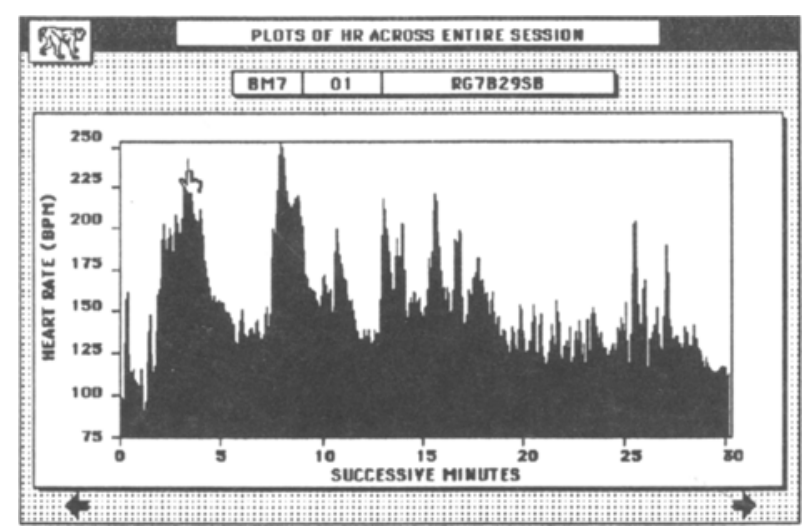

Figure 7. Data summary card: heart rate summarized across 30 consecutive minutes.

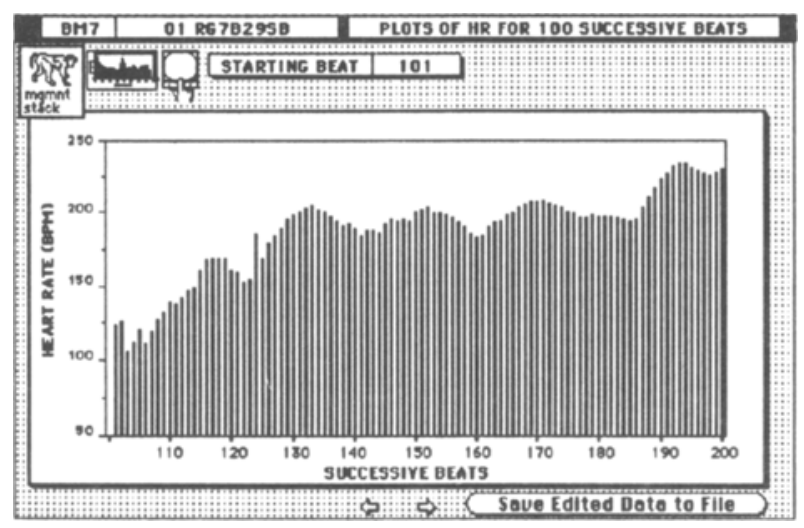

Figure 8. Beat-by-beat plot of heart rate corresponding to data summary card (Figure 7 ).

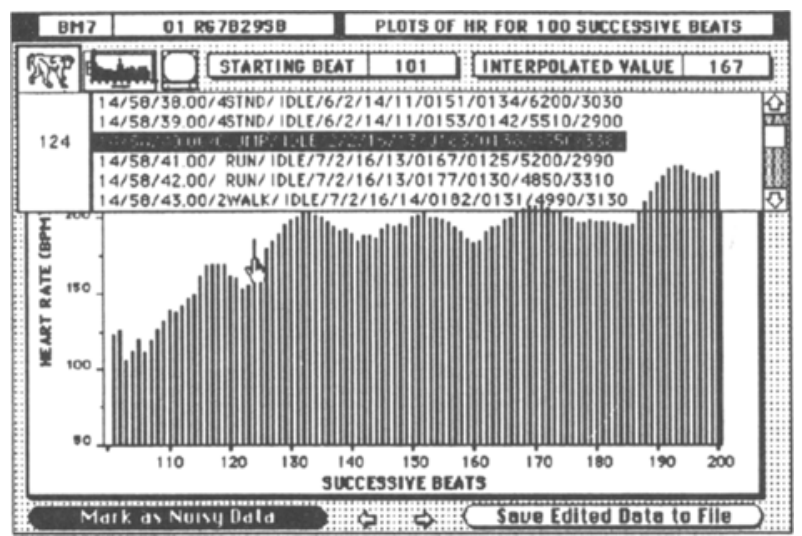

Figure 9. Beat-by-beat plot card showing file entry corresponding to Beat 124 (Figure 8).

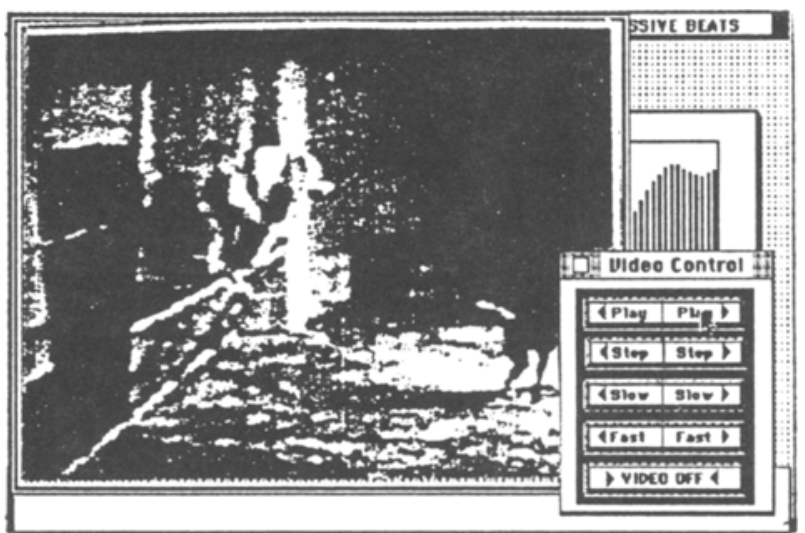

Figure 10. Beat-by-beat plot card showing video of the animal behavior associated with file entry of Beat 124 (Figure 9).

rate at Beat 124. Clicking on this beat brings the file entry from which this plot was created, which includes both the behavioral descriptions and the concurrent physiological measures (Figure 9). The file indicates that the animal began a jump at just this time. If the user is interested in what this jump looks like in the original behavioral setting, he/she clicks on the video icon at the top of the card (Figure 9) and a video of the animal in midair suddenly comes into view (Figure 10). The video-player control panel beside the video picture allows for control of fullmotion, slow-motion, or frame-by-frame viewing of what happened before or after this behavioral initiation. And this backward tracing from data summary to primary event illustrates in reverse how the data were coded and analyzed in the first place! The video is an integral part of the database and is accessible for preview or review.

Also included is an electronically upgraded version of the Astley et al. (1991) paper that describes the coding system used for the behavioral analysis of this demonstration. That electronic version of the publication includes coding definitions illustrated by randomly accessed video illustrations. Imagine the possibilities for hypermedia al- 
ternatives to traditional print-only scientific journals (see Ray \& Mitchell, in press). One could just as easily receive a video copy of the full experiment that generated the data, the statistical package used to analyze the data, and the traditional text-and-graphics summary, all in one package (e.g., on CD-ROM). And the entire unit could be easily cross-linked for direct access from one layer to another. Even the entire reference section could be scanned and included as a corpus of related articles.

\section{HYPERMEDIA PRODUCTION}

The BehSys Anal library is authored in Apple Computer's HyperCard and compiled BASIC and relies on several other commercially available add-on packages and $\mathrm{X}$-commands, including MacroMind Director and AddMotion's color-animation software as well as Voyager's Pioneer LDV-8000 interface package. We currently work on a development platform composed of a Macintosh Ifx with 4-MB RAM and a Rastor Ops 364 frame-grabber video-display board. We use a Pioneer LDV- 8000 video laser-disc player capable of random access using either a CAV or CLV disc format. This is important because we incorporate both commercial discs and in-houseproduced video materials that are transferred to single-copy DRAW laser discs. We are eagerly awaiting the impending development and availability of digital video technologies, such as Apple Computer's systems-level QuickTime and SuperMac's Video Spigot, which will allow video recording and editing directly to computer discs. This will truly bring availability of interactive video technologies into the hands of most teaching professionals.

The development of quality hypermedia products is a complex process that typically involves sizable development teams. Considerations such as subject content, instructional design, programming capabilities, and media production must all be orchestrated to produce quality interactive media. The process begins by establishing goals and objectives for each module. Textual materials offering introductory and extended readings must be selected and scanned via optical character reading equipment. Commercial videodiscs must be cataloged and repurposed and video footage must be selected from tape and film libraries for edited clips to be digitized and incorporated into the library. Graphics must be produced for concepts best illustrated graphically, and it must be determined where animation should be used for further emphasis. Flow charts are designed that display text, videos, and other media inputs as they are incorporated. Graphic and animated sequences must be designed that make the most impact on motivation, attention, and conceptual clarification. Programs and scripts are written to follow the prepared flow charts and storyboards, which ensures that the materials are linked in meaningful ways to the informational hypermedia network. The product must then be tested to debug the programs/scripts, and evaluations must be made to direct revisions and upgrades. The process is complex, despite the advances in technology that make it all possible.
Our experience with multimedia and hypertext resource module development has resulted in the development of the BehSys Anal hypermedia resource library. As with any library, there is always room for new acquisitions, and it thus is never to be considered a completed entity. Rather, one must describe it in terms of the current "number of volumes" (in this case, resource modules) it presently incorporates, as well as the levels of sophistication in learning it makes available. Using these criteria, we have barely begun to truly develop what qualifies as a "library," but we do have enough illustrations to demonstrate most features that such a library will eventually incorporate. The modules described above, including the working prototypes of the AI engine and the AKG components, in addition to the animated graphic simulation of operant conditioning (see Ray, in press), are working applications of a 20-year research program on behavioral systems analysis (Ray, 1972; Ray \& Brown, 1975, 1976; Ray \& Delprato, 1989; Ray \& Ray, 1976; Ray, Upson, \& Henderson, 1977; Upson \& Ray, 1984).

Although current designs for the tutorial and monitoring systems are based upon our own conceptual models of behavioral systems (Ray \& Delprato, 1989), they have many similarities to systems developed quite independently and from various alternative perspectives. In our approach, text construction is based on knowledge networks, whereby associative paths (and strength of connectivity) among fundamental units are used to develop the concepts of different functional clusterings, or levels of knowledge integration. How one creates effective communication of the knowledge networks has less empirical research to guide us, but beginnings do exist, as with research on the kinds of student-teacher interaction that take place in a tutorial situation (Collins, 1987). But research on relative strengths of presentation formats (i.e., text, graphics, animations, simulation, full-motion film or video), how to respond to a learner's questions, and how to effectively time activities such as presentation, questions, evaluation, and example offerings has been only partially developed (Reigeluth, 1988). One means for adapting these various alternatives to individual needs for timing is the use of a blackboard control architecture (HayesRoth, 1985), whereby AI engines are used to monitor an individual's performance and to aid in choosing the timing of route access and element choice. There is also a significant contribution to be made by applying a "competent systems," as opposed to an "expert systems," approach, as suggested by Abramson (1990) in his use of "influence" networks. In fact, such networks have a very strong relation to our own behavioral kinematic analysis approach (Ray \& Delprato, 1989).

Much of the foundation for content in our approach has similarities to various schemes of knowledge representation found in modern cognitive science, even though our approach has been guided more by descriptive behavioral analyses. The concept of a basic unit of knowledge as a building block is fundamental to our system, as it is in Minsky's (1975) frames, Rumelhart's (1975) schemata, Schank's (1976) scripts, Newell and Simon's (1972) pro- 
ductions, Rosenbloom and Newell's (1987) use of Miller's (1956) concept of the chunk, and Williams's (1991) rules. At issue is what we call the "terminological element," its "associative network," and its "conceptual path." A broad intellectual concept is broken down into its terminological elements, and their relative strength of association is assessed by a knowledge expert. These elements are then arranged into clusters and networks of clusters, whereby a student is able to navigate among clusters according to the associative paths assigned by the knowledge expert. Since many alternative paths to a given cluster may exist, the concept of a hypertext approach (Horney, 1991) to textual elements was a natural extension of the approach, with graphic illustrations, simulations, and full-motion digital video coming as natural extensions of hypertext (Ambron \& Hooper, 1988; Yankelovich, Meyrowitz, \& van Dam, 1987). Our final approach turned out to have much in common with Woolf's (1990) detailing of the fundamental tools her team uses in the design and construction of knowledge-based tutoring systems for computer-delivered instruction.

Our approach also is very sensitive to the issues discussed by Brandt (1990) concerning the difference between teaching and tutoring. Bloom (1984), in a very influential paper on the "two-sigma problem," demonstrates that when tutoring is compared to classroom learning, individual tutoring results in a two-standard-deviation (sigma) improvement in performance. Yet in his review of technologybased instructional systems currently in use, Brandt (1990) found that almost all were designed around a teaching, as opposed to a tutorial, design. This approach continues, despite evidence from researchers such as Anderson, Boyle, Farrell, and Reiser (1984), who found that a LISP tutor they designed performed the equivalent of $10 \mathrm{~h}$ of classroom instruction in less than $1 \mathrm{~h} 40 \mathrm{~min}$. The critical element here is the supply of sufficient intelligence to offer: (1) hints to overcome distractors that might lead to incorrect responses, (2) alternative presentations of equivalent information, and (3) parallel questioning. Most systems reviewed by Brandt only offered the answer in response to incorrect responding.

The modules we have developed, and are continuing to develop, utilize the tutorial model. In addition, they offer us direct information on the user's strategies and choices. This allows generation of feedback for development and design alteration that Woolf (1990) articulates as having been so critical in the development cycle. It also generates a highly usable database for ongoing research and evaluation of different learning styles and is anticipated to become the foundation for future research projects on these topics.

\section{CONCLUSIONS}

The BehSys Anal library was developed as a prototype. It continues to be developed and is not yet fully implemented. Nevertheless, several useful lessons have been learned thus far in its development. First, we have found HyperCard to be a fully adequate authoring environment for creating a relatively sophisticated second-level courseware system. We are currently working on porting the essence of the library's navigational and AI/AKG systems into a stand-alone shell authoring system that is intended for use by advanced undergraduate student assistants in their development of specialized teaching modules for our introductory psychology course. Although they are not yet complete or tested, early models, which incorporate a specialized menu bar full of developer's tools, show real promise for use by anyone who has a reasonable understanding of HyperCard but is not a proficient HyperTalk programmer.

Second, the lessons learned from our continuing refinement of the animated operant-conditioning simulator are sufficient for a whole series of specialized articles, the first of which is already complete (Ray, in press). Details of this component are far too complex for present elaboration, but it should be pointed out that the simulator has already suggested the need for multiple levels of control via kinematic matrix calculations that are specific for a variety of different settings depicted in the graphics, including when the animal is in the open field, near trees, and has food available. We anticipate that the parametric requirements of this simulator, which are presently established by guessing, will eventually lead to highly specific research projects that promise to give a whole new definition to both stimulus- and response-generalization gradients.

Finally, student response to our system has not yet been evaluated in application. Recent advancements of computer-related technologies for instruction have made a significant impact on the pedagogical strategies used at all levels of education. Research, though, has primarily focused on comparisons of computer-assisted instruction with conventional instruction. The results consistently show that not only is interactive videodisc instruction preferred to traditional methods, but it is also more effective at giving results in both knowledge and performance outcomes and in shortening the time needed to complete instruction (Grenier, 1991, p. 104).

In recent years, a body of research has emerged that addresses the many complexities involved in hypermedia development (e.g., Abramson, 1990; Bork \& Pomicter, 1990; Brandt, 1990; Carlson \& Falk, 1990; Flynn, 1990; MacKenzie, 1990; Miller \& Ruberg, 1990; Nelson \& Watson, 1991; Williams, 1991). Determining the quality and effectiveness of each module and its pedagogical value is complex. As suggested by Reeves (1991), in his guidelines for redirecting evaluation and research of interactive multimedia, research on these topics must "embrace the complexity and attempt to see it from many different perspectives" (p. 89). We believe the behavioral systems methodology used for the development of this library will be well suited to its evaluation and still meet these standards.

Computer-assisted instruction and interactive instructional video also offer some of the most precise research tools available to date for helping to understand the complexities of learning. We will be gathering a large data- 
base on learning styles, and we hope to examine such variables as self-pacing, feedback, and interactivity. As suggested by Williams and Brown (1990), assessment of these kinds of variables will provide knowledge on many issues related to learning psychology (e.g., the impact of the structure of knowledge on acquisition and retrieval of learning, the role of interactivity in learning, and the role of prior knowledge).

\section{REFERENCES}

Abramson, B. (1990). Competent systems: Effective, efficient, deliverable. Joumal of Interactive Instruction Development, 3(2), 9-15.

Ambron, S., HoOPER, K. (Eds.). (1988). Interactive hypermedia. Redmond, WA: Microsoft Press.

Anderson, J. R., Boyle, C. F., FArrell, R., \& Reiser, B. J. (1984). Cognitive principles in the design of a computer tutor (Tech. Rep. No. ONR-84-1). Arlington, VA: Office of Naval Research, Personnel and Training Research Programs.

Astley, C. A., Smith, O. A., Ray, R. D., Golanov, E. V., Chesney, M. A., Chalyan, V. G., Taylor, D. J., \& Bowden, D. M. (1991). Integrating behavior and cardiovascular responses: The code. American Joumal of Physiology, 261, R172-R181.

ВLоOм, B. S. (1984). The two-sigma problem: The search for methods of group instruction as effective as one-on-one tutoring. Educational Researcher, 13, 3-10.

Bork, A., \& Pomicter, N. (1990). Practical tochniques useful in authoring tochnology-based learning material. Journal of Computer-Based Instruction, 17(2), 53-60.

BrandT, R. (1990). Interactive means tutoring, NOT teaching. Journal of Interactive Instruction Development, 2(4), 8-10.

CArLson, H. L., * FALK, D. R. (1990). Interactive learning models using videodiscs in college and inservice instruction. Computers in Human Services, 7(3-4), 277-293.

Coluns, A. (1987). A sample dialogue based on a theory of inquiry teaching. In C. M. Reigeluth (Ed.), Instructional theories in action: Lessons illustrating selected theories and models (pp. 181-199). Hillsdale, NJ: Erlbaum.

FLYNN, J. P. (1990). Using the computer to teach and learn social policy: A report from the classroom and field. Computers in Human Senvices, 7(3-4), 199-209.

Grenter, J. M. (1991). Interactive multimedia instruction: What do the numbers show? In Ninth Annual Conference - Interactive Instruction Delivery (pp. 100-104). Orlando, FL: Society for Applied Learning Technology.

HA YES-ROTH, B. (1985). A blackboard architecture for control. Artificial Intelligence, 26(3), 251-321.

HoRney, M. A. (1991). Uses of hypertext. Joumal of Computing in Higher Education, 2(2), 44-65.

MacKenzie, I. S. (1990). Courseware evaluation: Where's the intelligence? Joumal of Computer Assisted Leaming, 6(4), 273-285.

MARTIN, J. (1990). Hyperdocuments and how to create them. Englewood Cliffs, NJ: Prentice-Hall.

Miller, G. A. (1956). The magical number seven, plus or minus two: Some limits on our capacity for processing information. Psychological Review, 63, 81-97.

Miller, M. G., Ruberg, L. F. (1990). Putting the end-user first: A challenging but promising concept. Journal of Interactive Instruction Development, 3(2), 20-25.
Minsky, M. (1975). A framework for representing knowledge. In P. H. Winston (Ed.), The psychology of computer vision (pp. 211-277). New York: McGraw-Hill.

Nelson, C. S., Watson, J. A. (1991). Multimedia and repurposed interactive videodisc courseware: The means to teacher authored content-rich learning materials. Joumal of Interactive Instruction De. velopment, 3(3), 10-15.

Newell, A., Simon, H. A. (1972). Human problem solving. Englewood Cliffs, NJ: Prentice-Hall.

RAY, R. D. (1972). Use of the conditional reflex to assess the temporal characteristics of curarization effects on heart rate responding. Conditional Reflex, 7, 19-32.

RAY, R. D. (in press). Interbehavioral methodology: Lessons from a simulator. In A. Hawkins \& T. Sharpe (Eds.), Field systems analysis: In search of the expert pedagogue [Monograph]. Joumal of Teaching in Physical Education.

RAY, R. D., \& Brown, D. A. (1975). A systems approach to behavior. Psychological Record, 25, 459-478.

RAY, R. D., Brown, D. A. (1976). The behavioral specificity of stimulation: A systems approach to procedural distinctions of classical and instrumental conditioning. Pavlovian Joumal of Biological Sciences, 11, 3-23.

RAY, R. D., \& DelPIATo, D. J. (1989). Behavioral systems analysis: Methodological strategies and tactics. Behavioral Science, 34, 81-127.

RAY R. D., MrtchelL, N. (in press). Good-bye scientific joumals: Tomorrow's scientific communications. In Seventh Annual Conference: Learning technology in the health care sciences. Warrenton, VA: Society for Applied Learning Technology.

RAY, R. D., \& RAY, M. R. (1976). A systems approach to behavior: II. The ecological description and analysis of human behavior dynamics. Psychological Record, 26, 147-180.

RAY, R. D., Upson, J. D., * Henderson, B. J. (1977). A systems approach to behavior: III. Organismic pace and complexity in timespace fields. Psychological Record, 27, 649-682.

ReEVEs, T. C. (1991). Ten commandments for evaluation of interactive multimedia in higher oducation. Joumal of Computing in Higher Education, 2(2), 84-113.

Reigeluth, C. M. (1988). Instructional theory in action: Lessons ilIustrating selected theories and models. Hillsdale, NJ: Erlbaum.

Rosenbloom, P., Newell, A. (1987). Learning by chunking: A production system model of practice. In P. Klahr, P. Langley, \& R. Neches (Eds.), Production system models of leaming and development (pp. 221-286). Cambridge: MIT Press.

RumelharT, D. E. (1975). Notes on a schema for stories. In D. G. Bobrow \& A. Collins (Eds.), Representation and understanding (pp. 211-236). New York: Academic Press.

SCHANK, R. C. (1976). The role of memory in language processing. In C. N. Cofer (Ed.), The structure of human memory (pp. 162-189). San Francisco: Freeman.

UPSON, J. D., RAY, R. D. (1984). An interbehavioral systems model for empirical investigation in psychology. Psychological Record, 34, 497-524.

Wiluams, C. J., Brown, S. W. (1990). A review of the research issues in the use of computer-related technologies for instruction: An agenda for research. International Joumal of Instructional Media, 17(2), 95-107.

WiLuAams, K. E. (1991). The experimental classroom of the future. Journal of Interactive Instruction Development, 3(4), 9-18.

WoOLF, B. (1990). Tools for building knowledge-based tutors. Journal of Computing in Higher Education, 2(1), 103-129.

Yankelovich, N., Meyrowitz, N., * VAN Dam, A. (1987). Reading and writing the electronic book. IEEE Computer, 20, 15-30. 